\title{
Lyotropic Liquid Crystal to Soft Mesocrystal Transformation in Hydrated Salt-Surfactant Mixtures
}

\author{
Cemal Albayrak, Gözde Barım, and Ömer Dag*[a]
}

\begin{abstract}
Hydrated $\mathrm{CaCl}_{2}$, LiI, and $\mathrm{MgCl}_{2}$ salts induce self-assembly in nonionic surfactants (such as $\mathrm{C}_{12} \mathrm{H}_{25^{-}}$ $\left.\left(\mathrm{OCH}_{2} \mathrm{CH}_{2}\right)_{10} \mathrm{OH}\right)$ to form lyotropic liquid-crystalline (LLC) mesophases that undergo a phase transition to a new type of soft mesocrystal (SMC) under ambient conditions. The SMC samples can be obtained by aging the LLC samples, which were prepared as thin films by spin-coating, dip-coating, or drop-casting of a clear homogenized solution of water, salt, and surfactant over a substrate surface. The LLC mesophase exists up to a salt/surfactant mole ratio of 8,10 , and 4 (corresponding to 59,68 , and $40 \mathrm{wt} \%$ salt/surfactant) in the $\mathrm{CaCl}_{2}$, LiI, and $\mathrm{MgCl}_{2}$ mes-
\end{abstract}

ophases, respectively. The SMC phase can transform back to a LLC mesophase at a higher relative humidity. The phase transformations have been monitored using powder X-ray diffraction (PXRD), polarized optical microscopy (POM), and FTIR techniques. The LLC mesophases only diffract at small angles, but the SMCs diffract at both small and wide angles. The broad surfactant features in the FTIR spectra of the LLC mesophases become sharp and well resolved upon SMC forma-

Keywords: alkali metals • liquid crystals $\cdot$ mesophases $\cdot$ salts $\cdot$ surfactants tion. The unit cell of the mesophases expands upon SMC transformation, in which the expansion is largest in the $\mathrm{MgCl}_{2}$ and smallest in the $\mathrm{CaCl}_{2}$ systems. The POM images of the SMCs display birefringent textures with welldefined edges, similar to crystals. However, the surface of the crystals is highly patterned, like buckling patterns, which indicates that these crystals are quite soft. This unusual phase behavior could be beneficial in designing new soft materials in the fields of phase-changing materials and mesostructured materials, and it demonstrates the richness of the phase behavior in the salt-surfactant mesophases.

\section{Introduction}

Self-assembly of surfactants into lyotropic liquid-crystalline (LLC) mesophases takes place in various solvents such as water, organics, ionic liquids, and some salts. ${ }^{[1-5]}$ We have shown that molten hydrated salts of the form $\left[\mathrm{M}\left(\mathrm{H}_{2} \mathrm{O}\right)_{m}\right] \mathrm{X}_{n}$ (in which $\mathrm{M}$ is a transition-metal ion such as $\mathrm{Mn}^{\mathrm{II}}, \mathrm{Co}^{\mathrm{II}}, \mathrm{Ni}^{\mathrm{iI}}$, $\mathrm{Zn}^{\mathrm{II}}, \mathrm{Cd}^{\mathrm{II}}$, and so forth, and $\mathrm{X}$ is a suitable anion such as $\mathrm{NO}_{3}{ }^{-}, \mathrm{Cl}^{-}$, and $\mathrm{ClO}_{4}^{-}$) that have melting points close to room temperature (RT) can act as the solvent component in the surfactant self-assembly. ${ }^{[5]}$ The molten hydrated salt-surfactant mixtures exhibit common LLC mesostructures (hexagonal, cubic, lamellar, and so forth) over a broad range of salt concentrations. ${ }^{[5]}$ Later, inspired by the analogy between the molten hydrated salts and concentrated aqueous electrolyte solutions, we discovered the LLC mesophases of $\mathrm{LiX} \cdot y \mathrm{H}_{2} \mathrm{O} / \mathrm{C}_{12} \mathrm{EO}_{10}$ (in which $\mathrm{X}$ is $\mathrm{NO}_{3}{ }^{-}, \mathrm{Cl}^{-}$, or $\mathrm{ClO}_{4}{ }^{-}$, and $y$ can be as low as $2 ; \mathrm{C}_{12} \mathrm{EO}_{10}$ is 10 -lauryl ether: $\mathrm{C}_{12} \mathrm{H}_{25^{-}}$ $\left.\left(\mathrm{OCH}_{2} \mathrm{CH}_{2}\right)_{10} \mathrm{OH}\right){ }^{[6]}$

[a] Dr. C. Albayrak, G. Barım, Prof. Ö. Dag

Department of Chemistry, Bilkent University

06800, Ankara (Turkey)

Fax: (+90)312-260-4068

E-mail: dag@fen.bilkent.edu.tr

Supporting information for this article is available on the WWW under http://dx.doi.org/10.1002/chem.201301662.
In the molten hydrated salt-surfactant systems, the water molecules are mostly coordinated to the metal ion. ${ }^{[5]}$ However, in the concentrated (hydrated salt) systems, the water molecules interact weakly with the metal ion and form the hydration sphere. Both mesophases are stable in open air at ambient conditions in contrast to most water/ $\mathrm{C}_{12} \mathrm{EO}_{10}$ mesophases, in which the surfactant molecules are unable to retain the water molecules. ${ }^{[1]}$ The higher stability in the saltsurfactant LLC mesophases is due to a stronger hydrogenbonding interaction between the molten salt (usually the water molecules coordinated to a metal ion) and ethylene oxide groups of the surfactant domains at the molten saltsurfactant interface. The salt-surfactant systems are also important in the synthesis of mesostructured and mesoporous metal-containing materials ${ }^{[7]}$ and as ion-conducting gel electrolytes. ${ }^{[6,8]}$

Prior to our studies of salt-surfactant systems, the electrolytes were regarded as additives in the water-surfactant mesophases. ${ }^{[9]}$ The salt concentrations were kept low and the motivation was to investigate the effect of salts on the phase behavior. ${ }^{[8]}$ However, our results indicated that the phase behavior of salt-surfactant systems becomes increasingly diverse and unique when the salt component is regarded as the main component in the self-assembly process. In the molten hydrated salt-surfactant and concentrated electrolyte solutions-surfactant systems, the high concentration of the salts increases the extent of the salt-surfactant inter- 
actions and also the cation effects (cation effects are less significant in dilute systems). Therefore, each salt-surfactant system has its own characteristics, and their phase behavior cannot be easily foreseen because of the complications arising from an increasing number of interactions: cation-water, anion-water, cation-surfactant, anion-surfactant, and cation-anion. However, the complicated picture also lends itself to new discoveries. In this study, we demonstrate such an example. A new mesophase-a mesocrystalline phasethat has properties between those of an LLC and a solid is presented for the first time using salt-surfactant systems. To distinguish them from the previously known mesocrystals, we have changed the term to soft mesocrystals (SMCs). These new SMCs can also be considered a new type of lyotropic plastic crystals. Plastic crystal phases of some organic molecules that show thermotropic liquid-crystalline behavior are also known in the literature. ${ }^{[10]}$ Additionally, LLC mesophases have been used as a media to synthesize mesostructured solids through several steps known as liquid-crystalline templating (LCT). ${ }^{[1]}$ In the LCT process, the freshly prepared mixture is in a liquid phase that undergoes transformation to a LLC phase, then to a soft plasticlike mesostructure, and finally to a mesostructured solid over time. ${ }^{[1]}$ However, the LLC, plasticlike mesostructured soft matter, and the final mesostructured solid only diffract at small angles (no diffraction lines at wide angles).

The concept of "mesocrystals" (i.e., ordered solid materials with periodic, mesoscale-length features) has been recently reviewed in a few papers that point out the importance of these nonclassical crystals. ${ }^{[12-19]}$ There are examples of mesocrystals ranging from biominerals to functional materials. ${ }^{[12]}$ Mesocrystals are usually obtained by a self-assembly process of colloidal nanocrystals that are crystallographically oriented by surfactants and polymers in a superstructure and are usually solid materials. ${ }^{[12-18]}$ Building blocks in these nonclassical crystals are usually nanomaterials with well-defined shape and size. ${ }^{[14]}$ The synthesis of mesocrystals is carried out through a series of chemical reactions to form nanoparticles and self-assembly processes using organic directing agents and bottom-up approaches. ${ }^{[13]}$ Therefore, the shape as well as the size uniformity of the building blocks are very important in the design of new mesocrystals of various compositions with new functions. ${ }^{[13,15]}$ There are also many examples of mesocrystalline biominerals in nature. ${ }^{[17,18]}$ These minerals are mechanically very stable. Therefore, understanding the underlying principles of mesocrystal formation may lead us to advanced new functional materials for various applications, which are well summarized by Cölfen. ${ }^{[12]}$ However, there are not yet examples of ionic mesocrystals or lyotropic plastic crystals with unit-cell parameters on the mesoscale length in the literature. Note that molecular or ionic building blocks usually produce bulk crystals or form LLC mesophases at room temperature.

Herein, we show that the $\mathrm{CaCl}_{2} \cdot x \mathrm{H}_{2} \mathrm{O} / \mathrm{C}_{12} \mathrm{EO}_{10}, \mathrm{LiI} \cdot x \mathrm{H}_{2} \mathrm{O}$ / $\mathrm{C}_{12} \mathrm{EO}_{10}$, and $\mathrm{MgCl}_{2} \cdot x \mathrm{H}_{2} \mathrm{O} / \mathrm{C}_{12} \mathrm{EO}_{10}$ mixtures form LLC mesophases that crystallize over time into soft mesocrystals at RT and can transform into LLC mesophases at higher hu- midity. We define the intermediate phase as mesocrystals because their unit-cell parameters are on the mesoscale length similar to those of the collodical mesocrystals. However, our mesocrystals are soft compared to the colloidal ones therefore we named the new phase "soft mesocrystals" (SMCs). The SMCs have been investigated using powder Xray diffraction (PXRD), polarized optical microscopy (POM), scanning electron microscopy (SEM), FTIR spectroscopy, and alternating-current (AC) impedance conductivity techniques.

\section{Results and Discussion}

Fresh films of the $\mathrm{CaCl}_{2} \cdot x \mathrm{H}_{2} \mathrm{O} / \mathrm{C}_{12} \mathrm{EO}_{10}$ mesophases: The LLC samples (either as thin films or drop-cast gels) were investigated under ambient conditions; therefore, the water concentration in the samples varied with the relative humidity $(\mathrm{RH})$ of the laboratory. The samples exhibit LLC mesophases at $\mathrm{CaCl}_{2} / \mathrm{C}_{12} \mathrm{EO}_{10}$ mole ratios between 1.0 and 8.0 (corresponding to 15 to $59 \mathrm{wt} \%$ salt/surfactant). Figure S1 in the Supporting Information shows the XRD patterns of the samples at different mole ratios collected at $24^{\circ} \mathrm{C}$ and $23 \% \mathrm{RH}$. The XRD patterns consist of 2 or 3 diffraction lines at most. Samples with 1.0 and 2.0 salt/surfactant mole ratios have 3 diffraction lines at $2 \theta=1.63(54.2 \AA), 1.68$ $(52.5 \AA)$, and $3.25^{\circ}(27.2 \AA)$; and 1.59 (55.5 $\left.\AA\right), 1.67$ $(52.8 \AA)$, and $3.25^{\circ}(27.2 \AA)$, respectively. The samples with higher $\mathrm{CaCl}_{2} / \mathrm{C}_{12} \mathrm{EO}_{10}$ mole ratios give only one diffraction line except the samples with mole ratios of 6.0 and 8.0, which have two diffraction lines at $61.3,59.6 \AA$ and 63.5 , $61.3 \AA$, respectively (see Figure S1 in the Supporting Information). Nevertheless, the POM images of the liquid-crystalline samples with salt/surfactant mole ratios below 3.0 display a characteristic fan texture and those 3.0 and higher provide dark POM images. Therefore, the structure is hexagonal up to 3.0, and cubic above a 3.0 salt/surfactant mole ratio. The hexagonal-to-cubic phase transition is common in salt-surfactant mesophases with increasing solvent (saltwater couple) in the mesophase, similar to water-surfactant mesophases. $^{[5]}$

Aged samples of the $\mathrm{CaCl}_{2} \cdot \boldsymbol{x} \mathrm{H}_{2} \mathrm{O} / \mathrm{C}_{12} \mathrm{EO}_{10}$ system: The spincoated samples, which were prepared from homogeneous solutions of the $\mathrm{CaCl}_{2} \cdot x \mathrm{H}_{2} \mathrm{O} / \mathrm{C}_{12} \mathrm{EO}_{10}$ mixtures, were aged under ambient conditions and various humidity conditions using a temperature- and humidity-controlled oven. The fresh thin films were in an LLC mesophase that transformed to SMCs over time. Usually, the LLC films are too thin to be able to observe a birefringent texture by POM, however, the SMC thin films are strongly birefringent. Figure 1 shows the POM images obtained during the LLC to SMC transformation. Figure $1 \mathrm{~A}$ displays an SMC nucleation from a defect site on the glass surface. Figure 1B shows the growth of the SMC from an edge of the glass slide. Figure 2 shows the shape and morphology of the SMCs, obtained from the samples, in which the $\mathrm{CaCl}_{2} / \mathrm{C}_{12} \mathrm{EO}_{10}$ mole ratio 

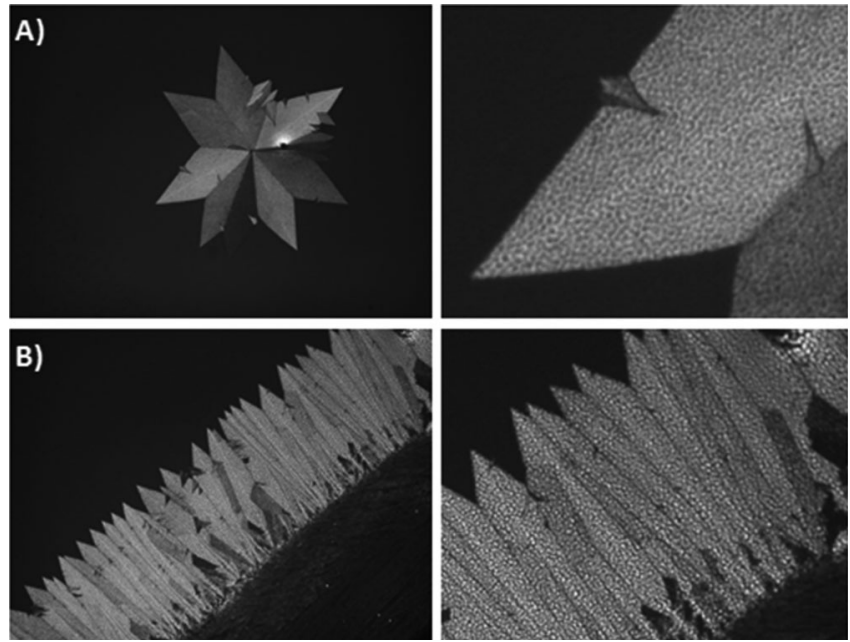

Figure 1. POM images of the crystallization process of the $\mathrm{CaCl}_{2} \cdot x \mathrm{H}_{2} \mathrm{O}$ / $\mathrm{C}_{12} \mathrm{EO}_{10}$ sample with a $\mathrm{CaCl}_{2} / \mathrm{C}_{12} \mathrm{EO}_{10}$ mole ratio of 2.0. A) Growth of an $\mathrm{SMC}$ from a defect site and $\mathrm{B}$ ) growth of an SMC from the edge of the sample (images on the right are magnified).

varies from 1.0 to 8.0. As shown in the POM images, the SMCs have well-defined crystal edges with many microdo-
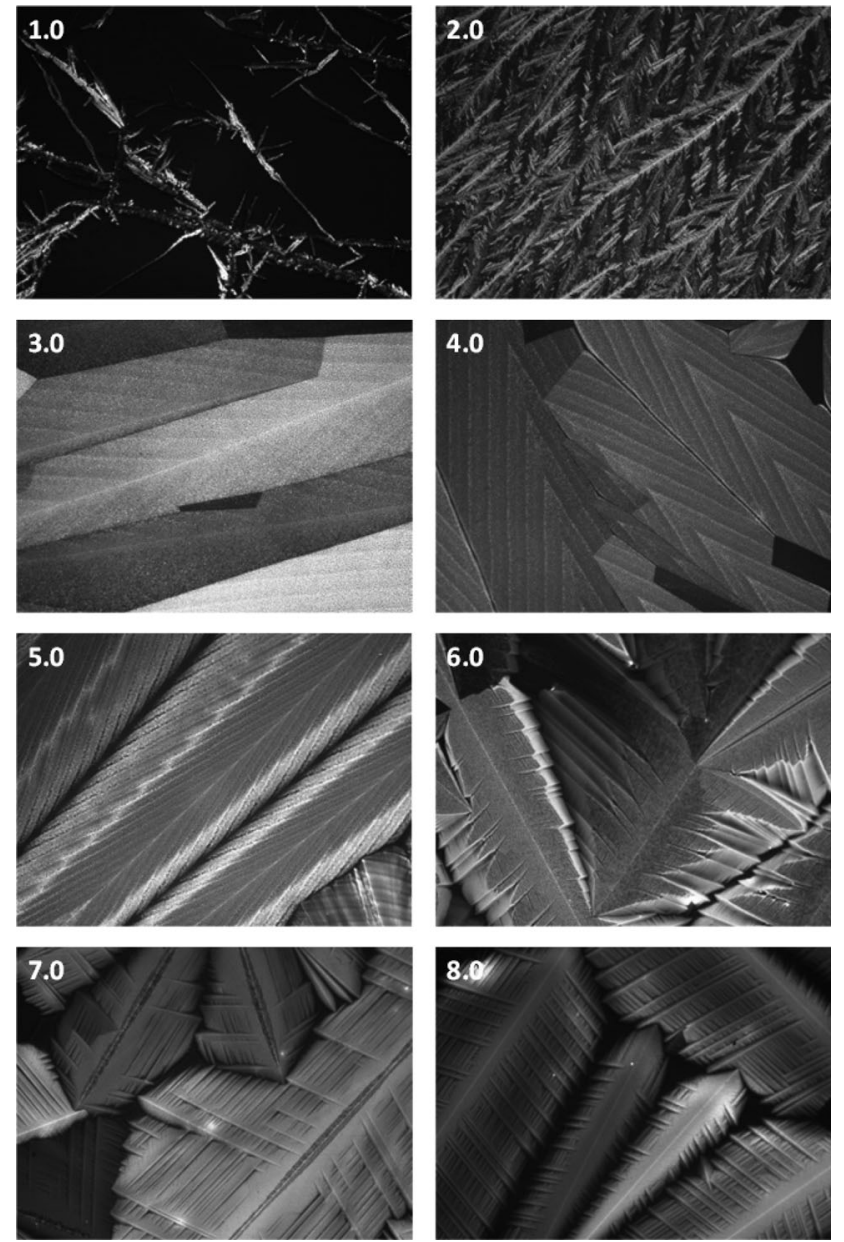

Figure 2. POM images of the aged $\mathrm{CaCl}_{2} \cdot x \mathrm{H}_{2} \mathrm{O} / \mathrm{C}_{12} \mathrm{EO}_{10}$ samples at different $\mathrm{CaCl}_{2} / \mathrm{C}_{12} \mathrm{EO}_{10}$ mole ratios (as shown in the images). mains compared to the fan texture, characteristic of the LLC mesophase. Most of the time, we have observed that the surface of the samples become completely covered with the soft mesocrystals in several hours. However, in some cases the mesocrystal formation may take days. The aged films were scratched using a sharp object to demonstrate the soft nature of the mesocrystals (Figure S2a in the Supporting Information). No crack formation is observed upon scratching, which indicates that the mesocrystals are soft, and collecting these crystals by scraping them from the glass slides gives plasticlike soft materials (Figure S2b in the Supporting Information). Notice also that the SMCs are birefringent at all compositions, which indicates that there is also an isotropic-to-anisotropic phase change during mesocrystallization at higher salt ratios.

We have also investigated the behavior of SMCs at higher temperatures and humidity levels. At all compositions, the SMC texture disappears with a dark image between the crossed polarizers above $49^{\circ} \mathrm{C}$, when heated in open air. Scratching the samples above this temperature results in remnants of powders, this means that the samples solidify. Figure $\mathrm{S} 3$ in the Supporting Information shows the FTIR spectra of the $\mathrm{CaCl}_{2} \cdot x \mathrm{H}_{2} \mathrm{O} / \mathrm{C}_{12} \mathrm{EO}_{10}$ mesocrystals during a heating experiment under open air. The sharp water peaks (in the $3100-3700 \mathrm{~cm}^{-1}$ region) and the surfactant peaks of the SMCs become broad at around $49^{\circ} \mathrm{C}$ together with a decrease in the intensity of the $v(\mathrm{OH})$ band of water. It seems that heating the SMC sample causes water to evaporate and the SMCs are destroyed at $49^{\circ} \mathrm{C}$ (see Figures S3 and S4 in the Supporting Information). A sample with two phases, LLC + SMC, was sandwiched between glass slides-to avoid water evaporation-and followed during the heating process by POM. We observed that the SMCs disappear at a higher temperature, around $90^{\circ} \mathrm{C}$, when the water evaporation was prevented (see Figure S5 in the Supporting Information). A sample that contained the two phases was deliberately chosen to monitor a possible SMC-to-LLC transition. However, we observed that the sample did not melt congruently. Regions of dark bubbles started to appear, indicative of a separation of the water-rich and water-poor domains. A direct transition from the SMC to LLC could not be observed in this way. However, the SMC-to-LLC phase transformation occurs if the relative humidity in the air is increased. The LLC samples, which were obtained from the SMCs, convert slowly back to SMCs. All of the SMC samples transform to LLC mesophases at RT under $55 \% \mathrm{RH}$ except the sample with a salt/surfactant mole ratio of 2.0 that transforms at RT under $60 \% \mathrm{RH}$.

The small- and wide-angle XRD patterns of the aged samples of the above compositions are shown in Figure S6 in the Supporting Information. Note that at wide angles, there are a very limited number of diffraction lines with very weak intensities. However, the thicker samples, obtained by dip-coating or -casting, display more diffraction lines at wide angles. The small-angle region shows significant changes with aging (see below). The most ordered sample, with a $\mathrm{CaCl}_{2} / \mathrm{C}_{12} \mathrm{EO}_{10}$ mole ratio of 2.0 , provides two diffraction 
lines at $2 \theta=1.32(66.8 \AA)$ and $2.64^{\circ}$ (33.4 $\AA$ ). At higher $\mathrm{CaCl}_{2} / \mathrm{C}_{12} \mathrm{EO}_{10}$ mole ratios, the $d$ spacing expands up to $69.5 \AA$, which is quite large for a salt/ $\mathrm{C}_{12} \mathrm{EO}_{10}$ LLC mesophase. The calculated $d$ spacing, obtained from the smallangle diffraction line of the fresh and aged sample with a $\mathrm{CaCl}_{2} / \mathrm{C}_{12} \mathrm{EO}_{10}$ mole ratio of 2.0 shifts from 55.5 to $66.8 \AA$ upon LLC-to-SMC transformation, corresponding to a $20 \%$ expansion. The lack of crystalline diffraction lines related to $\mathrm{CaCl}_{2}$ and its hydrated derivatives indicate that the observed crystallites are in the form of SMCs. The nature of the diffraction lines of the mesocrystals will be discussed further using LiI and $\mathrm{MgCl}_{2}$ systems.

SEM images of the $\mathrm{CaCl}_{2} \cdot x \mathrm{H}_{2} \mathrm{O} / \mathrm{C}_{12} \mathrm{EO}_{10}$ (3.0 mole ratio) mesocrystal thin film, spin-coated over a silicon wafer, were also recorded (see Figure S7 in the Supporting Information). The SEM images display a similar pattern to those observed by POM. No salt crystals were observed in the images, which indicated that the salt species are still in the mesostructure. The salt species did not crystallize during the several hours of SEM investigation. The typical vacuum in the SEM chamber was around $10^{-6}$ torr. Under such a low pressure, it is likely that most of the water is removed from the mesostructure, which makes the thin film crack (see Figure S7 in the Supporting Information). The crack pattern guides the defect pattern of the original LLC mesophase. Note also that the sample is beam-sensitive and undergoes deformation upon further focusing. Therefore high-resolution imaging could not be recorded.

To elucidate the nature of the salt species and surfactants, we also performed AC impedance conductivity and FTIR measurements, respectively, of the samples in the LLC and SMC phases. The conductivity measurements were carried out using a $\mathrm{CaCl}_{2} / \mathrm{C}_{12} \mathrm{EO}_{10}$ sample with a mole ratio of 3.0. The sample was prepared in glass vials and aged for 10 days to obtain the SMC phase (see Figure S8 in the Supporting Information). The conductivity measurement shows that the conductivity decreases slightly with mesocrystallization (from 0.067 to $0.026 \mathrm{~S} \mathrm{~cm}^{-1}$ ) but still displays very high ionic conductivity. The sample was followed for several days after mesocrystallization and no appreciable change was detected (see Figure S8 in the Supporting Information). High ionic conductivity indicates that the salt species are still solvated in the mesocrystals and are quite mobile. Further studies are needed to investigate the details of the conductivity, which is outside the scope of this investigation. To understand the nature of the surfactants in the SMCs we also measured the FTIR spectra of the samples under various conditions.

FTIR spectral investigation of the $\mathrm{CaCl}_{2} \cdot x \mathrm{H}_{2} \mathrm{O} / \mathrm{C}_{12} \mathrm{EO}_{10}$ SMC thin films: To clarify our observations on the phase transition and crystallization, the FTIR spectra of the LLC and SMC samples of $\mathrm{CaCl}_{2} \cdot x \mathrm{H}_{2} \mathrm{O} / \mathrm{C}_{12} \mathrm{EO}_{10}$ were recorded. Figure $\mathrm{S} 9$ in the Supporting Information shows the FTIR spectra of fresh samples of $\mathrm{CaCl}_{2} / \mathrm{C}_{12} \mathrm{EO}_{10}$ with mole ratios between 1.0 and 5.0. There is a decreasing trend in the $v(\mathrm{CO})$ stretching frequency of the ethylene oxide group with increasing salt concentration, which indicates an in- creasing strength in the hydrated metal-ion-surfactant interactions. $^{[5]}$ Under the same experimental conditions, the water- $\mathrm{C}_{12} \mathrm{EO}_{10}$ mesophases are unstable and the samples cannot retain the water molecules. In the LLC samples of $\mathrm{CaCl}_{2} \cdot x \mathrm{H}_{2} \mathrm{O} / \mathrm{C}_{12} \mathrm{EO}_{10}$, the intensity of the water band at around $3000-3700 \mathrm{~cm}^{-1}$ increases with an increasing salt concentration. This means that the water molecules are kept in the mesophase in the form of hydrated water. Additionally, the water bands are found to be at a significantly higher wavenumber, compared to transition-metal salt analogues, ${ }^{[19]}$ owing to the lack of covalent coordination of water molecules to the metal center.

The FTIR spectra of the LLC and SMC samples exhibit significant differences in almost every region of the spectra (Figure 3). Aged samples display sharper and distinct peaks
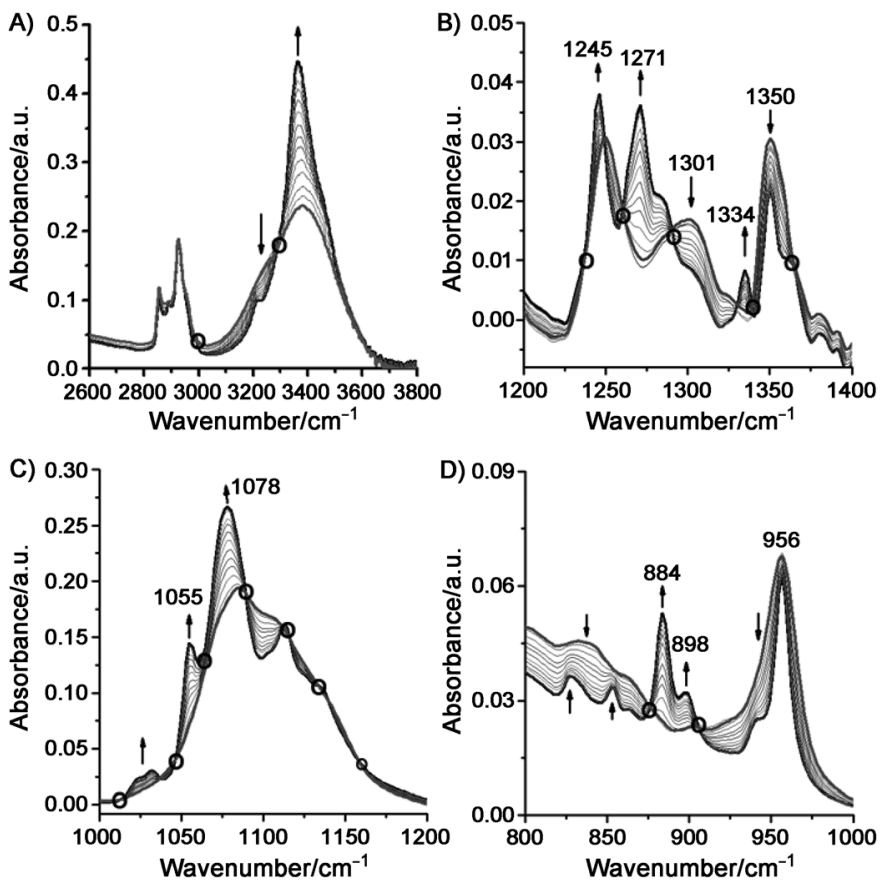

Figure 3. FTIR spectral changes during the cooling process of $\mathrm{CaCl}_{2} \cdot x \mathrm{H}_{2} \mathrm{O} / \mathrm{C}_{12} \mathrm{EO}_{10}$ with a $\mathrm{CaCl}_{2} / \mathrm{C}_{12} \mathrm{EO}_{10}$ mole ratio of 2.0 (arrows show the direction of change). See text for details.

originating from the SMCs. In addition, water molecules are kept in the SMCs, which indicate that salt, water, and surfactant collectively crystallize into an SMC phase. The sharp water peaks (in the $3100-3700 \mathrm{~cm}^{-1}$ region) and the surfactant peaks of the SMCs become broad at around $49^{\circ} \mathrm{C}$ (Figure S3 in the Supporting Information), which indicate the evaporation of some water from the media and a transformation of the SMC to a disordered phase, respectively. The SMC to disordered solid mesostructure transformation in open air is reversible and the spectral changes during cooling from $49^{\circ} \mathrm{C}$ to RT are much smoother and better for monitoring the adsorption of water. In addition, the spectra of the SMC samples and the SMC sample obtained after the cooling process are exactly the same. Therefore, the spectral 
changes were recorded during the cooling step (Figure 3). To simplify the discussion, the spectra have been divided into four different spectral regions: 3700-2800, 1400-1200, 1200-1000, and 1000-750 $\mathrm{cm}^{-1}$.

The $3700-2800 \mathrm{~cm}^{-1}$ region (Figure $3 \mathrm{~A}$ ) originates from the $v(\mathrm{CH})$ stretching modes of the alkyl and ethoxy methylenes $\left(2800-3000 \mathrm{~cm}^{-1}\right)$ and water (between 3000 and $3600 \mathrm{~cm}^{-1}$ ) species. The SMC sample has distinct and sharp peaks in the water region. There is a relatively sharp $v(\mathrm{OH})$ signal at $3363 \mathrm{~cm}^{-1}$, a shoulder at $3445 \mathrm{~cm}^{-1}$, and a small peak at $3212 \mathrm{~cm}^{-1}$. These well-defined structures in the water signals indicate the presence of crystalline-like water molecules in the mesocrystals. In the $2800-3000 \mathrm{~cm}^{-1}$ region the intensity of the peak at $2889 \mathrm{~cm}^{-1}$ increases with mesocrystallization. There is also a new peak emerging at $2989 \mathrm{~cm}^{-1}$ in this region, which may be indicative of a new conformation of the surfactants (this will be discussed further using the other spectral features).

The $1400-1200 \mathrm{~cm}^{-1}$ region is mostly occupied by the peaks due to the bending mode of the methylene and the stretching of the $\mathrm{C}-\mathrm{C}$ bonds of the surfactant molecules. The region gives important information about the conformation of the ethylene oxide backbone (Figure 3B). Note that polyethylene oxide (PEO) has a helical structure owing to the presence of the trans $(\mathbf{T})-$ gauche $(\mathbf{G})$-trans $(\mathbf{T})$ conformation (TGT) along the $-\mathrm{O}-\mathrm{CH}_{2}-\mathrm{CH}_{2}-\mathrm{O}$ - segment in the crystalline state. ${ }^{[20]}$ Spectroscopic studies on PEO and water mixtures show that the $\mathrm{C}-\mathrm{C}$ bond prefers the $\mathbf{G}$ conformation with an increasing water concentration. ${ }^{[21]}$ The $\mathrm{C}-\mathrm{O}$ bond, however, has a higher tendency towards the $\mathbf{T}$ conformation with increasing water concentration. A similar behavior is also observed in the transition-metal salt $/ \mathrm{C}_{12} \mathrm{EO}_{10}$ LLC mesophases. ${ }^{[5,19]}$ In the transition-metal salt $/ \mathrm{C}_{12} \mathrm{EO}_{10}$ systems, the ethylene oxide chains have a higher preference for the TGT sequence along the $-\mathrm{O}-\mathrm{CH}_{2}-\mathrm{CH}_{2}-\mathrm{O}$ - segments as compared to $\mathrm{H}_{2} \mathrm{O} / \mathrm{C}_{12} \mathrm{EO}_{10}$ systems. ${ }^{[19]}$ The conformational differences were attributed to the stronger salt ion-surfactant interactions through stronger hydrogen bonding arising from the coordinated water molecules. ${ }^{[19]}$

The key peaks in the $1400-1200 \mathrm{~cm}^{-1}$ region originate from the $\mathrm{CH}_{2}$ wagging mode of the $\mathrm{C}-\mathrm{C}\left(-\mathrm{H}_{2} \mathrm{C}-\mathrm{CH}_{2}-\right)$ bond and the $\mathrm{CH}_{2}$ twisting mode for the $\mathrm{C}-\mathrm{O}\left(-\mathrm{H}_{2} \mathrm{C}-\mathrm{O}-\right)$ bond. ${ }^{[20,21]}$ The $\mathbf{G}$ conformer was assigned to the 1350 $1355 \mathrm{~cm}^{-1}$ region and the $\mathbf{T}$ conformer was assigned to the $1325-1335 \mathrm{~cm}^{-1}$ region for the $\mathrm{C}-\mathrm{C}$ bond. ${ }^{[20]}$ For the $\mathrm{C}-\mathrm{O}$ bond, the $\mathbf{G}$ conformer was observed at $1310-1290 \mathrm{~cm}^{-1}$ and the $\mathbf{T}$ conformer was observed at $1295-1270 \mathrm{~cm}^{-1}$. ${ }^{[20]}$ The FTIR spectra in this region show significant changes together with many isosbestic points during the cooling step (see Figure 3). The isosbestic points are good indications of a single-step transformation of the LLC mesophases to SMC or in this case from a disordered phase to SMC. The peak at $1350 \mathrm{~cm}^{-1}$, corresponding to the $\mathbf{G}$ conformer of the $\mathrm{C}-\mathrm{C}$ bond, ${ }^{[21]}$ loses its intensity and the peak at $1334 \mathrm{~cm}^{-1}$, owing to the $\mathbf{T}$ conformer of the $\mathrm{C}-\mathrm{C}$ bond, enhances over time during the transformation. The intensity of the $\mathbf{G}$ conformer of the $\mathrm{C}-\mathrm{O}$ bond at $1301 \mathrm{~cm}^{-1}$ also decreases, where- as the peak at $1271 \mathrm{~cm}^{-1}$ together with a shoulder of the $\mathbf{T}$ conformer intensifies. Both changes indicate that there is a significant increase in the $\mathbf{T}$ conformer population of both $\mathrm{C}-\mathrm{C}$ and $\mathrm{C}-\mathrm{O}$ bonds. However the signals related to $\mathbf{G}$ conformers do not disappear completely, which indicate that the ethylene oxide chains are partially extended by increasing their $\mathbf{T}$ conformer population.

The antisymmetric twisting modes of the $-\mathrm{O}-\mathrm{CH}_{2}-\mathrm{CH}_{2}-\mathrm{O}$ segment, observed at around 1265-1250 and 1245-1230 $\mathrm{cm}^{-1}$ were assigned to TGG and TGT conformers, respectively. ${ }^{[21]}$ The signal at $1251 \mathrm{~cm}^{-1}$ was previously assigned to the TGG conformer. ${ }^{[21]}$ In the FTIR spectra, during mesocrystallization, the peak at $1251 \mathrm{~cm}^{-1}$ shifts to $1245 \mathrm{~cm}^{-1}$ and becomes sharper. This means that there is also an increase in the $\mathbf{T}$ conformer of the $\mathrm{C}-\mathrm{O}$ bond, in accordance with the above statements. It was previously mentioned that the $\mathrm{C}-\mathrm{O}$ bond is not affected by the increase in the hydrogen bonding as compared to the $\mathrm{C}-\mathrm{C}$ bond. ${ }^{[20]}$ It is the $\mathbf{G}$ conformer of the $\mathrm{C}-\mathrm{C}$ bond that allows $\mathrm{PEO}-$ solvent interactions and the $\mathrm{C}-$ $\mathrm{O}$ bond that allows the flexibility. ${ }^{[20]}$ Therefore the variations on the $\mathrm{C}-\mathrm{C}$ bond are more pronounced in the $\mathrm{PEO}-$ solvent interactions. Overall, this spectral region shows that the population of the $\mathbf{T}$ conformer for both $\mathrm{C}-\mathrm{C}$ and $\mathrm{C}-\mathrm{O}$ bonds increase, which may also explain the increasing unit cell in the SMCs.

The $1200-1000 \mathrm{~cm}^{-1}$ region is dominated by the $\mathrm{C}-\mathrm{O}$ stretching vibrations and does not show conformational dependence. ${ }^{[21]}$ However, the signals of the $\mathrm{C}-\mathrm{O}$ stretching modes become visible and well resolved (see Figure 3C) and display drastic changes with crystallization, which indicates stronger salt-surfactant interactions. Two new signals also emerge at 1023 and $1032 \mathrm{~cm}^{-1}$, which may indicate the presence of a direct $\mathrm{Ca}^{2+}-\mathrm{OCH}_{2} \mathrm{CH}_{2}$ - interaction. The 750 $1000 \mathrm{~cm}^{-1}$ region also shows significant changes with crystallization (Figure 3D). The peaks originate from the $\mathrm{CH}_{2}$ rocking modes of the surfactant. ${ }^{[20]}$ Sharp and well-resolved peaks are indications of the mesocrystallization of the surfactants with the salt species. The crystalline pure surfactant signals do not overlap with the observed SMCs signals. Two weak peaks at 905 and $922 \mathrm{~cm}^{-1}$ in the LLC mesophases disappear, while the new peaks at 884 and $898 \mathrm{~cm}^{-1}$ appear. The broad feature in the $800-880 \mathrm{~cm}^{-1}$ region resolves into 4 new peaks. The peak at $996 \mathrm{~cm}^{-1}$ loses its intensity and becomes sharp. This region is also sensitive to interactions between the metal ion and ethylene oxide groups. ${ }^{[22]}$ Overall, all these spectral changes can be assigned to conformational changes due to metal-surfactant interactions and crystallization.

The LLC mesophase to soft mesocrystal transformation in the $\mathrm{LiI} \cdot x \mathrm{H}_{2} \mathrm{O} / \mathrm{C}_{12} \mathrm{EO}_{10}$ and $\mathrm{MgCl}_{2} \cdot x \mathrm{H}_{2} \mathrm{O} / \mathrm{C}_{12} \mathrm{EO}_{10}$ systems: The LLC to SMC transformation is not limited to the $\mathrm{CaCl}_{2} \cdot x \mathrm{H}_{2} \mathrm{O} / \mathrm{C}_{12} \mathrm{EO}_{10}$ systems; similar phase changes were also observed in the $\mathrm{LiI} \cdot x \mathrm{H}_{2} \mathrm{O} / \mathrm{C}_{12} \mathrm{EO}_{10}$ and $\mathrm{MgCl}_{2} \cdot x \mathrm{H}_{2} \mathrm{O} /$ $\mathrm{C}_{12} \mathrm{EO}_{10}$ LLC mesophases. The LLC mesophases slowly crystallize into SMCs in both systems and were also investigated to provide more insight into the LLC to SMC trans- 
formation. It is also likely that the other highly concentrated electrolyte solutions may form LLC mesophases that undergo a similar transformation. However, we were able to observe the SMC formation only for $\mathrm{CaCl}_{2}, \mathrm{LiI}$, and $\mathrm{MgCl}_{2}$ among many different salt systems. $\mathrm{Ca}\left(\mathrm{NO}_{3}\right)_{2} \cdot x \mathrm{H}_{2} \mathrm{O} / \mathrm{C}_{12} \mathrm{EO}_{10}$ undergoes an LLC to mesostructured solid transformation upon dehydration at higher temperatures, therefore it is kept out of the scope of this investigation.

The LiI $x \mathrm{H}_{2} \mathrm{O} / \mathrm{C}_{12} \mathrm{EO}_{10}$ mesophases can be prepared in exactly the same manner to $\mathrm{CaCl}_{2} \cdot x \mathrm{H}_{2} \mathrm{O} / \mathrm{C}_{12} \mathrm{EO}_{10}$ mesophases. The LLC samples diffract at small angles (as a single line, in most compositions, at around $2 \theta=1.5-1.8^{\circ}$ ) and display a birefringent fan texture (characteristic of the hexagonal mesophase) under $\mathrm{POM}$ at low $\mathrm{LiI} / \mathrm{C}_{12} \mathrm{EO}_{10}$ mole ratios (2 to 3.5). Figure 4(top) displays a typical POM image of the LLC sample of the $\mathrm{LiI} \cdot x \mathrm{H}_{2} \mathrm{O} / \mathrm{C}_{12} \mathrm{EO}_{10}$ mesophase at a $\mathrm{LiI} /$ $\mathrm{C}_{12} \mathrm{EO}_{10}$ mole ratio of 2 . The fan texture disappears in the POM image at a salt/surfactant mole ratio around 3.5, however they still diffract at small angles. The POM images and XRD patterns collectively show that the mesophase is hexagonal up to a salt $/ \mathrm{C}_{12} \mathrm{EO}_{10}$ mole ratio of 3.5 and then transforms to an isotropic cubic mesophase.

The LLC mesophases of the LiI $x \mathrm{H}_{2} \mathrm{O} / \mathrm{C}_{12} \mathrm{EO}_{10}$ system undergo a transition from an LLC to a SMC phase, which dif-
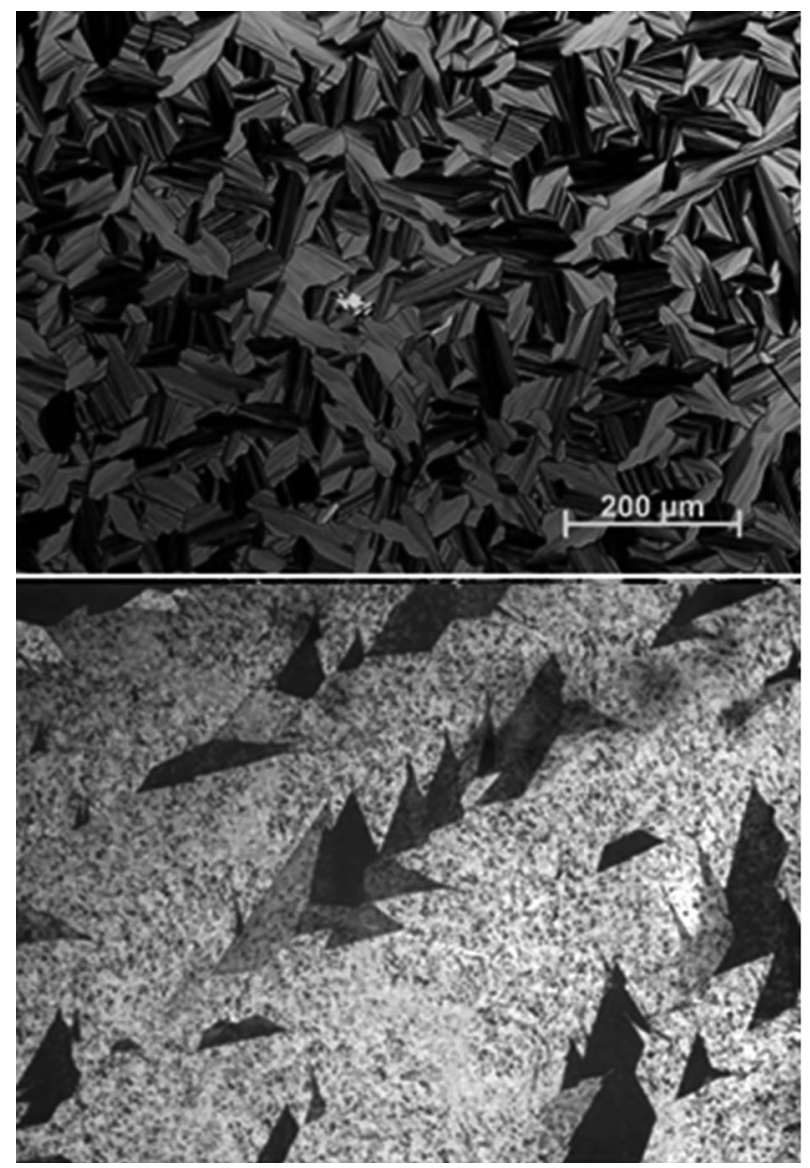

Figure 4. POM image of the (top) LiI $x \mathrm{H}_{2} \mathrm{O} / \mathrm{C}_{12} \mathrm{EO}_{10}$ LLC sample (LiI/ $\mathrm{C}_{12} \mathrm{EO}_{10}$ mole ratio is 2.0) and (bottom) LiI $x \mathrm{H}_{2} \mathrm{O} / \mathrm{C}_{12} \mathrm{EO}_{10}$ mesocrystal $\left(\mathrm{LiI} / \mathrm{C}_{12} \mathrm{EO}_{10}\right.$ mole ratio is 4.0$)$. fracts at both small and wide angles at high salt concentrations. Figure 4 displays POM images of the fresh (a thicker sample) and aged sample after phase transformation. Note also that there are only 1 or 2 diffraction lines in the smallangle region of the PXRD pattern of the LLC mesophase. However, with mesocrystallization, many new lines appear in the PXRD pattern of the SMC at both small and wide angles. Furthermore, the small-angle diffraction lines shifted to smaller angles, which indicate expansion of the unit cell upon transformation from the LLC phase to the SMC phase. The SMC film is also birefringent and the POM images show sharp-edged textures (like crystals), which are not characteristic of LLC samples. However, inside these birefringent SMC domains there is also a spongelike texture (not characteristic for normal crystals), which again rules out the possibility that the domains originate from the salt crystals. Note also that in the case of salt crystallization from the LLC media, one observes characteristic intense diffraction lines of the salt crystals and the FTIR spectrum display peaks of both salts and the molten surfactants as a mixture. However, the mesocrystals observed in Figure 4 (bottom) are soft and crystalline at the same time. Figure S10 in the Supporting Information shows the diffraction patterns of the LiI $x \mathrm{H}_{2} \mathrm{O} / \mathrm{C}_{12} \mathrm{EO}_{10}$ samples with $\mathrm{LiI} / \mathrm{C}_{12} \mathrm{EO}_{10}$ mole ratios of 2 to 8 . Clearly the diffraction line shifts to smaller angles upon increasing the salt amount in the mesophase and mesocrystals. The large expansion of the unit cell and the observed multiple diffraction lines can be attributed to mesocrystallization (see Figure S10 in the Supporting Information). The LLC to SMC transformation is clear at around a $\mathrm{LiI} / \mathrm{C}_{12} \mathrm{EO}_{10}$ mole ratio of 4.0. Below this ratio the mesocrystallization requires very low humidity and proceeds very slowly.

The phase transition of the LLC to SMC phase over time of the $\mathrm{LiI} \cdot x \mathrm{H}_{2} \mathrm{O} / \mathrm{C}_{12} \mathrm{EO}_{10}$ sample with a $\mathrm{LiI} / \mathrm{C}_{12} \mathrm{EO}_{10}$ mole ratio of 4.0 has been monitored using XRD. Figure 5 shows the changes in the XRD pattern of the sample during aging (from bottom to top) under ambient conditions. It is seen that the small-angle diffraction lines remain and shift to lower angles with crystallization and broad wide-angle diffraction lines appear. Clearly, there is a phase transition from a cubic LLC phase to a SMC phase. Notice that the fresh sample has a diffraction line at around $2 \theta=1.83^{\circ}$. However, after a few minutes a broad diffraction line starts to emerge at $2 \theta=1.55^{\circ}$, while the intensity of the diffraction lines at $2 \theta=1.83^{\circ}$ decreases. When the phase transition is complete (in about $1 \mathrm{~h}$, depends on the temperature and humidity), the $d$ spacing becomes $76.1 \AA$. The SMC phase has broader and weaker diffraction lines compared to the LLC cubic phase. This is reasonable because the orientation in the LLC phase is lost upon crystallization. At wide angles there are many diffraction lines, which are relatively broad and cannot be assigned to any LiI or LiI $x \mathrm{H}_{2} \mathrm{O}$ salt crystals (see Figure 6B). The small-angle diffraction line shifts from $2 \theta=1.84$ to $1.18^{\circ}(76.1 \AA)$ upon crystallization with two new lines at $2 \theta=2.29(38.5 \AA)$ and $3.49^{\circ}(25.4 \AA)$ that can be indexed to (100), (200), and (300) lines of the SMC, respec- 


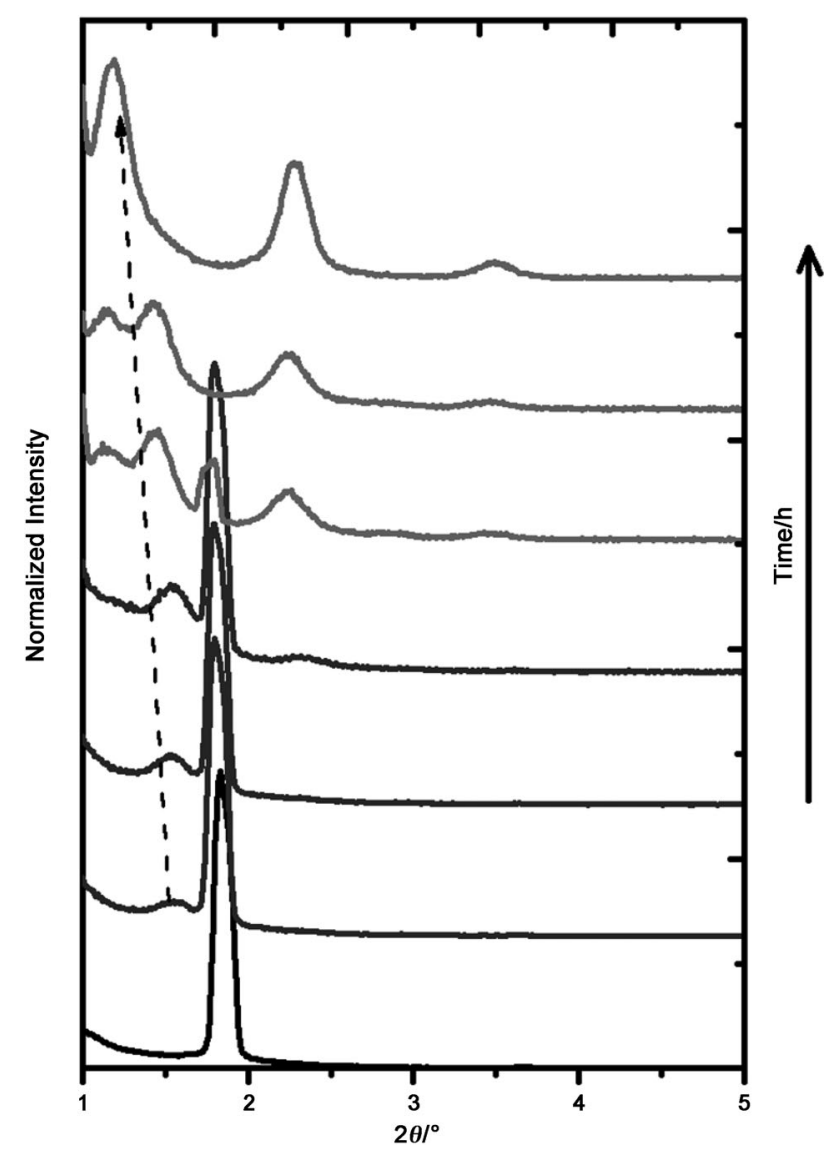

Figure 5. XRD pattern of the LLC (bottom) to SMC phase (top) transition of $\mathrm{LiI} \cdot x \mathrm{H}_{2} \mathrm{O} / \mathrm{C}_{12} \mathrm{EO}_{10}$ with a $\mathrm{LiI} / \mathrm{C}_{12} \mathrm{EO}_{10}$ mole ratio of 4.0 over time.
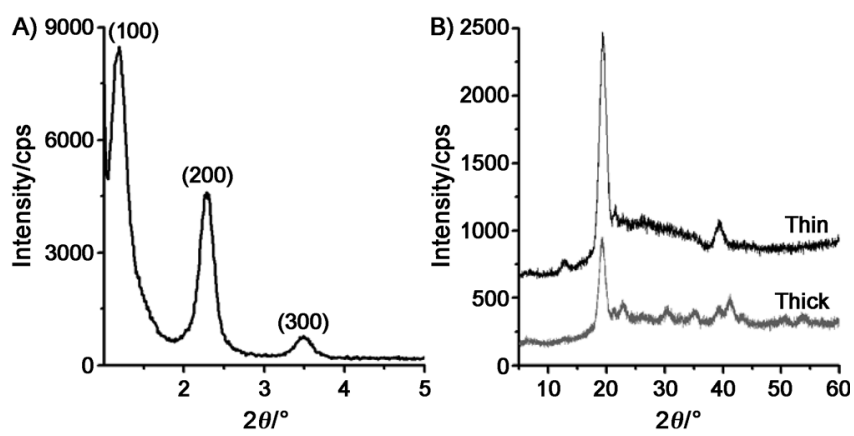

Figure 6. A) Small-angle and B) wide-angle XRD pattern of the mesostructured complex phase at high angles $\left(\mathrm{LiI} / \mathrm{C}_{12} \mathrm{EO}_{10}\right.$ mole ratio is 4.0$)$.

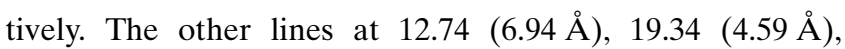
$21.48(4.13 \AA)$, and $39.36^{\circ}(2.29 \AA)$ can be indexed to $(002)$, (302), (308), and (604) of a rectangular structure with unitcell parameters of $a=87.8 \AA$ and $c=13.9 \AA$.

Casting the solution (LiI, water, and surfactant) produces thicker SMC samples that may have more intense diffraction lines at wide angles (see Figure 6). All the lines can be indexed with the same unit-cell parameters as its thin films. The only difference is the orientation of the mesocrystals that provide different intensity patterns. However, further studies are required to fully elucidate the structure of the SMCs.

The FTIR spectra of the same sample (at a salt/surfactant mole ratio of 4.0) are given in Figure 7, before and after the LLC to SMC phase transition. The spectra show significant changes upon phase transformation. Most of the surfactant

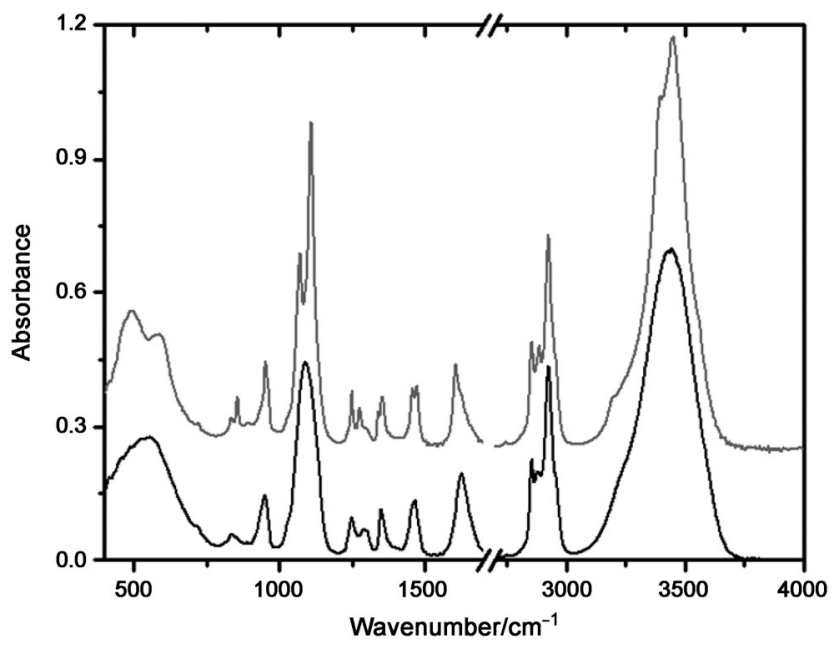

Figure 7. FTIR spectra of the LLC phase (bottom) and SMC phase (top) of LiI $x \mathrm{H}_{2} \mathrm{O} / \mathrm{C}_{12} \mathrm{EO}_{10}$ with a $\mathrm{LiI} / \mathrm{C}_{12} \mathrm{EO}_{10}$ mole ratio of 4.0.

signals split into their components, become sharper and more intense and new peaks arise that solely originate from the SMCs. Most significantly, two new peaks can be seen at 1276 and $1339 \mathrm{~cm}^{-1}$. The former was previously assigned to the $\mathrm{CH}_{2}$ twisting mode of the trans $\mathrm{C}-\mathrm{O}$ bond and the latter is assigned to the $\mathrm{CH}_{2}$ rocking mode of the trans $\mathrm{C}-\mathrm{C}$ bond of the ethylene oxide chain of the surfactant. ${ }^{[20-23]}$ Our discussions about the FTIR data for $\mathrm{CaCl}_{2} \cdot \mathrm{H}_{2} \mathrm{O} / \mathrm{C}_{12} \mathrm{EO}_{10}$ is also relevant to the LiI $\cdot x \mathrm{H}_{2} \mathrm{O} / \mathrm{C}_{12} \mathrm{EO}_{10}$ systems. That is, the intensity of the $\mathbf{T}$ conformers increases and that of the $\mathbf{G}$ conformers decreases. This causes an expansion of the surfactant domains and is consistent with our observation in the XRD patterns. Again, the changes in the surfactant signals cannot be attributed to surfactant crystals, which have a very different spectrum (compare spectra in Figures 7 and 8 ). The $\mathrm{C}_{12} \mathrm{EO}_{10}$ surfactant is in its molten phase under ambient conditions and displays broad FTIR absorption peaks (Figure S11 in the Supporting Information). Therefore, we crystallized the pure $\mathrm{C}_{12} \mathrm{EO}_{10}$ at a low temperature to collect and compare the FTIR spectra of the surfactant crystals (Figure S11 in the Supporting Information) with that of the SMCs. There are significant differences between the crystalline $\mathrm{C}_{12} \mathrm{EO}_{10}$ and SMCs. It is seen that the $v(\mathrm{CO})$ stretching band $\left(1000-1100 \mathrm{~cm}^{-1}\right)$ is redshifted in the SMCs owing to stronger metal-ion-ethylene oxide interactions. However, the conformational changes are also observed in the crystalline surfactant in the $1200-1400$ and $750-1000 \mathrm{~cm}^{-1}$ regions, which indicate that the origin of crystallization on the mesoscale is similar between the pure and salted surfactants. The 

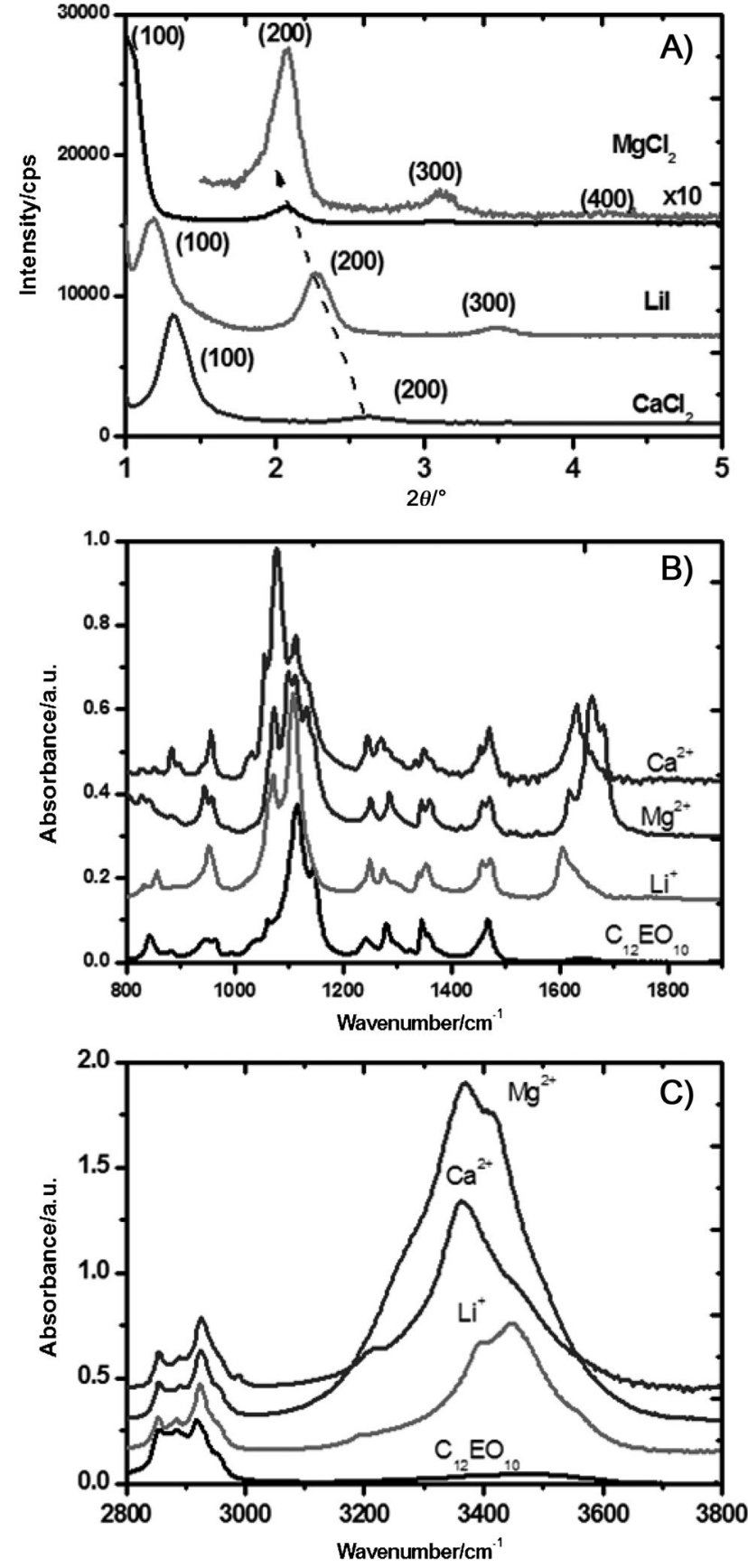

Figure 8. A) XRD patterns and B),C) FTIR spectra of the salt $x \mathrm{H}_{2} \mathrm{O}$ / $\mathrm{C}_{12} \mathrm{EO}_{10}$ mesocrystals (salts are $\mathrm{MgCl}_{2}, \mathrm{CaCl}_{2}$, or LiI as marked on the spectra) and crystalline $\mathrm{C}_{12} \mathrm{EO}_{10}$.

increasing $\mathbf{T}$ conformer population of the ethylene oxide chain enhances the surfactant-surfactant interactions, and as a result enhances the crystallization. However, the crystallization of pure surfactant requires a lower temperature. Similarly, the POM images, PXRD patterns, and AC conductivity data of the SMCs display significant differences from those of the LLC mesophases, crystalline surfactants, and salt crystals. The POM images of the SMCs indicate a crystal-like morphology with a soft nature, whereas the LLC phase displays a fan texture, the crystalline surfactant displays a birefringent texture with no definitive features, and the salt crystals appear as hard crystals. The PXRD patterns of SMCs also have many extra diffraction lines at both small and wide angles that do not exist in the PXRD patterns of the LLC mesophases and salt crystals. The small-angle diffraction lines are shifted to smaller angles that show larger unit-cell parameters in the SMCs compared to those in the LLC mesophases. The unit-cell expansion is also consistent with the FTIR results that show an increase of the $\mathbf{T}$ conformers and an expansion of the ethylene oxide domains of the surfactants in the SMCs. The AC conductivity also drops to around one third upon mesocrystallization, which indicates a reduced mobility of the ions in the SMC phase compared to the LLC mesophases.

It is also important to note that the formation of the SMCs is strongly dependent on the temperature and relative humidity in the air similar to the $\mathrm{CaCl}_{2} \cdot x \mathrm{H}_{2} \mathrm{O} / \mathrm{C}_{12} \mathrm{EO}_{10}$ systems. The mesocrystals reconstruct to an LLC mesophase above $25 \% \mathrm{RH}$ at RT. The samples that have higher salt concentrations have a greater tendency to form an SMC phase. For instance, the SMCs are observed for samples with a salt/surfactant mole ratio between 3.0 and 8.0 : in the $5.0-8.0$ mole ratios at $20 \% \mathrm{RH}$, and $3.0-5.0$ ratios at $15 \%$ $\mathrm{RH}$, both at RT. We also inspected the presence of a similar behavior by changing the counterion with $\mathrm{Cl}^{-}, \mathrm{Br}^{-}$, and $\mathrm{NO}_{3}{ }^{-}$ions. In light of the information that low humidity is a prerequisite for SMC formation, we investigated other salt systems with POM in a humidity oven between 0 and $50^{\circ} \mathrm{C}$. However, we did not observe any indication of such a transition in other $\mathrm{Li}^{\mathrm{I}}$ salt systems. A detailed investigation, under conditions of varying humidities and temperatures, should be carried out to reach a valid conclusion. Further investigations are needed to elucidate the structural details of this novel phase at a molecular level.

The $\mathrm{MgCl}_{2} \cdot x \mathrm{H}_{2} \mathrm{O} / \mathrm{C}_{12} \mathrm{EO}_{10}$ LLC mesophases are also stable up to $3.0 \mathrm{MgCl}_{2} / \mathrm{C}_{12} \mathrm{EO}_{10}$ mole ratio and can also undergo mesocrystallization (see Figure S12 in the Supporting Information). However, at higher salt concentrations, one can also observe $\mathrm{MgCl}_{2}$ crystals in the samples (see Figure $\mathrm{S} 12 \mathrm{~b}$ in the Supporting Information). The mesocrystals of the $\mathrm{MgCl}_{2} \cdot x \mathrm{H}_{2} \mathrm{O} / \mathrm{C}_{12} \mathrm{EO}_{10}$ system have been observed by using POM, and the XRD patterns show similar trends to those observed in the $\mathrm{CaCl}_{2} \cdot x \mathrm{H}_{2} \mathrm{O} / \mathrm{C}_{12} \mathrm{EO}_{10}$ and $\mathrm{LiI} \cdot x \mathrm{H}_{2} \mathrm{O} /$ $\mathrm{C}_{12} \mathrm{EO}_{10}$ samples. Similar to the above-mentioned SMC phases, the FTIR spectra display sharp and redshifted peaks upon mesocrystallization.

Figure 8 shows the XRD patterns and FTIR spectra of the SMCs of these three salts and crystalline $\mathrm{C}_{12} \mathrm{EO}_{10}$ for comparison. Figure $8 \mathrm{~A}$ shows the small-angle $\mathrm{XRD}$ patterns of the $\mathrm{MgCl}_{2}$, LiI, and $\mathrm{CaCl}_{2}$ samples at a salt/surfactant mole ratio of 2 except the LiI, which has 4 LiI per surfactant (the lowest stable mesocrystals of LiI form above a mole ratio of 4). The unit-cell parameters, on the mesoscale, are $102,87.8$, and $77.1 \AA$ in the $\mathrm{MgCl}_{2}, \mathrm{LiI}$, and $\mathrm{CaCl}_{2}$ samples, respectively. This means that the ethylene oxide units are fully expanded in the $\mathrm{MgCl}_{2} \cdot x \mathrm{H}_{2} \mathrm{O} / \mathrm{C}_{12} \mathrm{EO}_{10}$ and partially ex- 
panded in the $\mathrm{LiI} \cdot x \mathrm{H}_{2} \mathrm{O} / \mathrm{C}_{12} \mathrm{EO}_{10}$ and $\mathrm{CaCl}_{2} \cdot x \mathrm{H}_{2} \mathrm{O} / \mathrm{C}_{12} \mathrm{EO}_{10}$ SMCs through conformational changes of the ethylene oxide units. This is also evident in the FTIR spectra of these samples, in which the peaks due to the $\mathbf{T}$ conformer of the surfactant senses the metal ion and are the most intense in the $\mathrm{MgCl}_{2}$ and weakest in the $\mathrm{CaCl}_{2}$ systems (see Figure 8B and $8 \mathrm{C}$ ). Therefore there is a correlation between the unitcell parameter of the mesocrystals and the $\mathbf{T}$ conformer population of the surfactant molecules; the unit-cell expansion and $\mathbf{T}$ conformer population follow the same trend: $\mathrm{CaCl}_{2}<\mathrm{LiI}<\mathrm{MgCl}_{2}$. Since the $-\mathrm{OCH}_{2} \mathrm{CH}_{2} \mathrm{O}$ - units are fully extended in the $\mathrm{MgCl}_{2} \cdot x \mathrm{H}_{2} \mathrm{O} / \mathrm{C}_{12} \mathrm{EO}_{10}$ mesocrystals, this could be the major reason for the leaching out of the $\mathrm{MgCl}_{2}$ crystals at higher salt ratios (much lower than $\mathrm{CaCl}_{2}$ and $\mathrm{LiI}$ ). There is an inverse relationship between the expansion of the $-\mathrm{OCH}_{2} \mathrm{CH}_{2} \mathrm{O}$ - unit of the surfactant and its salt uptake. This is reasonable if we consider that the helical (G conformers) ethylene oxide solvates the salt and keeps the hydrated salt solution in the mesophases and SMCs. The water peaks, in the stretching and bending region, also reflect the same trend; the absorbed water is the largest in the $\mathrm{MgCl}_{2}$ and smallest in the LiI samples (but intermediate if the $\mathrm{H}_{2} \mathrm{O}$ /ion is considered), but they all display relatively sharp well-resolved water peaks relative to bulk water (see Figure $8 \mathrm{C}$ ). Further detailed vibrational and structural analysis is required to elucidate the structural details of the SMCs.

\section{Conclusion}

Spin-coating of clear aqueous solutions of LiI, $\mathrm{CaCl}_{2}$, and $\mathrm{MgCl}_{2}$ salts in the presence of oligo(ethylene oxide)-type surfactants form LLC thin films that crystallize over time into nonclassical crystals (mesocrystals or lyotropic plastic crystals). The freshly spun samples, over a broad range of salt/surfactant ratios, form LLC phases upon evaporation of the free water molecules during spinning; but upon aging at RT and under ambient humidity conditions, they transform into mesocrystals. The mesocrystals display very high ionic conductivity and never leach out the salt species even under high vacuum conditions. The mesocrystals undergo a phase change to an LLC mesophase at higher humidity. The unit cells of the mesocrystals are much larger than those of the LLC mesophases. The expansion of the unit cell is the largest in the $\mathrm{MgCl}_{2}$ system and smallest in the $\mathrm{CaCl}_{2}$ system. The origin of this expansion in the unit cell and the LLC-toSMC transformation is due to the transformation of the ethylene oxide units from the TGG conformation to a mostly TGT conformation. The hydration water of the ions and metal-ion-ethylene oxide interactions were identified; however, further studies are required to elucidate the structural details of these soft mesocrystals, which are believed to be the first such examples reported in the literature. The new SMCs and phase transitions take place at relatively low temperatures that may be useful in fields such as phase-changing materials and may also be important for investigating highly concentrated electrolyes in soft confined spaces. These findings show that the salt-surfactant systems have rich phase properties that require further investigation.

\section{Experimental Section}

Preparation of the samples in the solution phase: The required weights of salt and $\mathrm{C}_{12} \mathrm{EO}_{10}$ were dissolved in deionized water $(5 \mathrm{~mL})$ in glass vials and stirred for $6 \mathrm{~h}$ to ensure homogenization of the solution. For instance, in the preparation of $2 \mathrm{CaCl}_{2} / 1 \mathrm{C}_{12} \mathrm{EO}_{10}$-excess $\mathrm{H}_{2} \mathrm{O}$ (numbers depict the mole ratios), $\mathrm{CaCl}_{2} \cdot 6 \mathrm{H}_{2} \mathrm{O}(0.700 \mathrm{~g}), \mathrm{C}_{12} \mathrm{EO}_{10}(1.0 \mathrm{~g})$, and $\mathrm{H}_{2} \mathrm{O}$ $(5 \mathrm{~mL})$ were mixed and stirred for $6 \mathrm{~h}$ using a stirrer. The homogeneous solutions were then ready for further treatment. All other compositions of $\mathrm{CaCl}_{2} \cdot 6 \mathrm{H}_{2} \mathrm{O}$ (only the $\mathrm{CaCl}_{2} \cdot 6 \mathrm{H}_{2} \mathrm{O}$ amount was varied from 0.350 to $3.500 \mathrm{~g}$ ) and the other salts in all compositions (keeping the surfactant and water amounts constant) were prepared using the same procedure. Preparation of the $\mathrm{LiI} \cdot x \mathrm{H}_{2} \mathrm{O} / \mathrm{C}_{12} \mathrm{EO}_{10}$ gel samples: The samples were prepared with different compositions by keeping the surfactant amount constant $(1.0 \mathrm{~g})$. For example, in preparing the $3 \mathrm{LiI} \cdot 3 \mathrm{H}_{2} \mathrm{O} / 1 \mathrm{C}_{12} \mathrm{EO}_{10}$ sample (numbers depict the mole ratios), LiI $(0.641 \mathrm{~g}), \mathrm{H}_{2} \mathrm{O}(0.258 \mathrm{~g})$, and molten $\mathrm{C}_{12} \mathrm{EO}_{10}(1.000 \mathrm{~g})$ were weighed and mixed in a glass vial. The cap of the vial was then tightly sealed with a Teflon tape. The sample was then constantly shaken in a heating bath above the melting point of the composition for $24 \mathrm{~h}$ to ensure complete homogenization of the mixture. The $\mathrm{CaCl}_{2}, \mathrm{Ca}\left(\mathrm{NO}_{3}\right)_{2}$, and $\mathrm{MgCl}_{2}$ gel samples were prepared using the same method.

Preparation of thin LLC films: The LLC thin films were prepared by spin-coating the above homogenized solutions on glass slides or silicon wafers. A few milliliters of the solutions was put on glass slides or silicon wafers, which were then spun at 1000 or $750 \mathrm{rpm}$ for thin and thicker films, respectively. Then the films were either used for some measurements, such as FTIR and XRD, or visualized using POM.

Characterizations: XRD patterns were recorded on a Rigaku Miniflex diffractometer using a high-power $\mathrm{Cu}_{\mathrm{K} \alpha}$ source operating at $30 \mathrm{kV} / 15 \mathrm{~mA}$ and a wavelength of $1.5405 \AA$. The samples were either spin-coated over glass slides from the homogeneous solutions at $1000 \mathrm{rpm}$ or spread over glass sample holders. The measurements were made with $0.01-0.02^{\circ}$ intervals and $0.1-5^{\circ} \mathrm{min}^{-1}$ scan speed. The POM images were obtained in transmittance mode using a ZEISS Axio Scope.A1 microscope with a Linkam LTS350 temperature-controlling stage attached to the microscope. Temperature control was performed with a Linkam T95-LinkPad temperature programmer attached to the stage. The samples were investigated on glass slides, as substrates. For heating and cooling measurements the samples were sandwiched between two glass slides to avoid water evaporation. The cooling was achieved by computer-controlled pumping of the chamber with liquid $\mathrm{N}_{2}$, therefore the atmosphere of the chamber was practically $100 \% \mathrm{~N}_{2}$. The heating and cooling speeds were varied between $1-5^{\circ} \mathrm{min}^{-1}$. The images were captured/monitored using a camera attached on top of the microscope. The FTIR spectra were recorded using a Bruker Tensor 27 model FTIR spectrometer. A Digi Tect TM DLATGS detector was used with a resolution of $4.0 \mathrm{~cm}^{-1}$ in the 400 $4000 \mathrm{~cm}^{-1}$ range. The samples were either spin-coated onto IR-transparent Si substrates, from homogeneous solutions at $750 \mathrm{rpm}$, or spread as a thin layer from a gel sample. If the water content was to be analyzed, the samples were sandwiched between silicon wafers. During the measurements the temperature and humidity of the atmosphere was noted because the water content of the samples may vary with these parameters. The AC impedance conductivity measurements were carried out using a Gamry G750 potentiostat/galvanostat by using a home-made conductivity cell equipped with two stainless-steel electrodes. The cell constant of the conductivity apparatus was determined to be $0.67 \mathrm{~cm}^{-1}$ using a $0.01 \mathrm{M}$ standard $\mathrm{KCl}$ solution. The SEM images were collected using a ZEISS EVO-40 instrument operating at $10 \mathrm{kV}$. 


\section{Acknowledgements}

The authors thank TÜBİTAK under the project numbers $110 \mathrm{~T} 813$ and $112 \mathrm{~T} 407$ for financial support. Ö.D. is a member of Science Academy, Istanbul, Turkey.

[1] a) D. J.; Fang, B. Ding, H. Gleiter, Chem. Soc. Rev. 2011, 40, 5347 5360 Mitchell, G. J. T. Tiddy, L. Waring, T. Bostock, M. P. McDonald, J. Chem. Soc. Faraday Trans. I: Phys. Chem. Condensed Phases 1983, 79, 975-1000; b) K. Binnemans, Chem. Rev. 2005, 105, 4148 4204.

[2] A. Ray, J. Am. Chem. Soc. 1969, 91, 6511-6512.

[3] T. L. Greaves, C. J. Drummond, Chem. Soc. Rev. 2008, 37, 17091726.

[4] a) D. P. Siegel, Langmuir 2010, 26, 8673-8683; b) W. J. Zhou, W. Q. Gu, Y. J. Xu, C. S. Pecinovsky, D. L. Gin, Langmuir 2003, 19, 63466348.

[5] Ö. Çelik, Ö. Dag, Angew. Chem. 2001, 113, 3916-3919; Angew. Chem. Int. Ed. 2001, 40, 3800-3803; b) C. Albayrak, N. Özkan, Ö. Dag, Langmuir 2011, 27, 870-873.

[6] C. Albayrak, A. Cihaner, Ö. Dag, Chem. Eur. J. 2012, 18, 41904194.

[7] a) P. V. Braun, P. Osenar, S. I. Stupp, Nature 1996, 380, 325-327; b) C. J. Brinker, Y. Lu, A. Sellinger, H. Fan, Adv. Mater. 1999, 11, $579-585$; c) Y. Yamauchi, T. Ohsuna, K. Kuroda, Chem. Mater. 2007, 19, 1335-1342; d) Y. Türker, Ö. Dag, J. Mater. Chem. 2008, 18, 3467-3473.

[8] a) P. L. Kerr, S. A. Miller, R. K. Shoemaker, B. J. Elliott, D. L. Gin, J. Am. Chem. Soc. 2009, 131, 15972-1593; b) H. Shimura, M. Yoshio, K. Hoshino, T. Mukai, H. Ohno, T. Kato, J. Am. Chem. Soc. 2008, 130, 1759-1765; c) R. Q. Song, H. Cölfen, Adv. Mater. 2010, $22,1301-1330$.

[9] a) C. Rodríguez, H. Kunieda, Langmuir 2000, 16, 8263-8269; b) T. Iwanaga, M. Suzuki, H. Kunieda, Langmuir 1998, 14, 5775-5781.

[10] J. W. Goodby, G. W. Gray in Physical Properties of Liquid Crystals (Eds.: D. Demus, Goodby, G. W. Gray, H. W. Spiess, V. Vill), Wiley-
VCH, Weinheim, 1999, pp. 17-23, Chapter II: Guide to the Nomenclature and Classification of Liquid Crystals.

[11] G. S. Attard, J. C. Glyde, C. G. Göltner, Nature 1995, 378, 366-368.

[12] a) H. Cölfen, S. Mann, Angew. Chem. 2003, 115, 2452-2468; Angew. Chem. Int. Ed. 2003, 42, 2350-2365; < lit b $>$ H. Cölfen, M. Antonietti, Angew. Chem. 2005, 117, 5714-5730; Angew. Chem. Int. Ed. 2005, 44, 5576-5591.

[13] a) L. Zhou, P. O'Brien, Small 2008, 4, 1566-1574; b) J.; Fang, B. Ding, H. Gleiter, Chem. Soc. Rev. 2011, 40, 5347-5360.

[14] a) T. Wang, H. Cölfen, M. Antonietti, J. Am. Chem. Soc. 2005, 127, 3246-3247; b) J. Fang, B. Ding, X. Song, Cryst. Growth Des. 2008, 8, 3616-3622; c) S. H. Liu, J. Y. Gong, B. Hu, S. H. Yu, Cryst. Growth Des. 2009, 9, 203-209.

[15] S. Disch, E. Wetterskog, R. P. Hermann, G. Salazar-Alvarez, P. Busch, T. Brückel, L. Bergström, S. Kamali, Nano Lett. 2011, 11, $1651-1656$.

[16] P. Simon, E. Rosseeva, I. A. Baburin, L. Liebscher, S. G. Hickey, R. Cardoso-Gil, A. Eychmuller, R. Kniep, W. Carrillo-Cabrera, Angew. Chem. 2012, 124, 10934-10939; Angew. Chem. Int. Ed. 2012, 51, 10776-10781.

[17] Y. Oaki, A. Kotachi, T. Miura, H. Imai, Adv. Funct. Mater. 2006, 16, $1633-1639$

[18] J. Aizenberg, J. C. Weaver, M. S. Thanawala, V. C. Sundar, D. E. Morse, P. Fratzl, Science 2005, 309, 275.

[19] a) Ö. Dag, S. Alayoglu, C. Tura, Ö. Çelik, Chem. Mater. 2003, 15, 2711-2717; b) Ö. Dag, S. Alayoglu, I. Uysal, J. Phys. Chem. B 2004, 108, 8439-8446.

[20] R. Begum, H. Matsuura, J. Chem. Soc. Faraday Trans. 1997, 93, 3839-3848.

[21] H. Matsuura, K. Fukuhara, J. Poly. Sci. Part B-Poly. Phys. 1986, 24 , $1383-1400$.

[22] R. Frech, W. Huang, Macromolecules 1995, 28, 1246-1251.

[23] C. P. Rhodes, R. Frech, Macromolecules 2001, 34, 1365-1368.

Received: April 30, 2013

Revised: August 2, 2013

Published online: September 17, 2013 